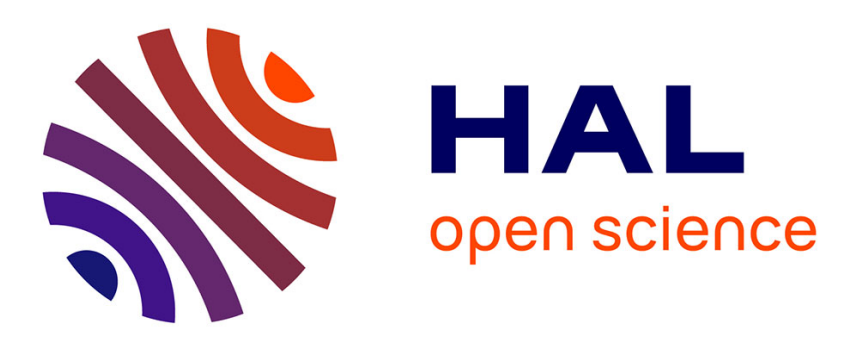

\title{
Knowledge Organization Systems and cultural interoperability in open humanitarian settings
}

Quoc-Tan Tran

\section{To cite this version:}

Quoc-Tan Tran. Knowledge Organization Systems and cultural interoperability in open humanitarian settings. Fifteenth International ISKO Conference: "Challenges and Opportunities for Knowledge Organization in the Digital Age", International Society for Knowledge Organization, Jul 2018, Porto, Portugal. hal-01833678

\section{HAL Id: hal-01833678 https://hal.science/hal-01833678}

Submitted on 9 Jul 2018

HAL is a multi-disciplinary open access archive for the deposit and dissemination of scientific research documents, whether they are published or not. The documents may come from teaching and research institutions in France or abroad, or from public or private research centers.
L'archive ouverte pluridisciplinaire HAL, est destinée au dépôt et à la diffusion de documents scientifiques de niveau recherche, publiés ou non, émanant des établissements d'enseignement et de recherche français ou étrangers, des laboratoires publics ou privés. 


\title{
Quoc-Tan Tran
}

\section{Knowledge Organization Systems and cultural interoperability in open humanitarian settings}

\begin{abstract}
This paper aims to identify the landscape of knowledge organization and representation applications developed in the open humanitarian data movement and consider how the high level of cultural interoperability can improve information exchange, the evaluation of humanitarian needs and the prioritization of humanitarian responses. Firstly, the paper presents reflections on the production, manipulation, and dissemination of open humanitarian data. Secondly, it discusses how knowledge organization meets the growing need to organize emerging forms of digital information. The case of Rohingya, a humanitarian disaster of historic proportion, is used to illustrate multilingual, cross-cultural, and social issues in knowledge organization and representation in humanitarian settings.
\end{abstract}

\section{Introduction}

Knowledge organization systems (KOS) have long been used as a means of information exchange and have functioned as standards in knowledge organization and resource discovery. The diversity of digital practices and the importance of knowledge consistency and reuse within systems in the cross-cultural and multicultural environment has attracted the attention of many authors and is becoming crucial for KOS and their interoperability (Barát 2008; García Gutiérrez 2002; Hudon 1999; López-Huertas 2008, 2016; Li Liew 2004). The need for global and local access to information in any language in any culture is an essential aspect of ethics in KO. Some authors in the literature have called for culturally warranted intercultural ethics and the goal of respecting cultural and linguistic diversity (Adler et al. 2016; Beghtol 2002, 2005; Hudon 1997; Mustafa El Hadi 2015; Tran 2017).

In the humanitarian domain, KOS enable humanitarian organizations to address needs with a better-coordinated response by improving information exchange, the representation of information needs, data relevance and overall effectiveness of retrieval. Nevertheless, attempts to standardize humanitarian data, and build a crisis ontology system have shown limited success (Di Maio 2007; Jihan and Segev 2013). It is common for agencies or information management officers to have to manually compile humanitarian data to fit specific requests (Warner and Obrecht 2016). Keßler and Hendrix noted that any proposed solution to improve coordination across agencies "should not require the replacement of existing information management systems, but rather focus on interoperability between existing systems" (Keßler and Hendrix 2015, 10). This paper firstly gives a brief overview of the recent open humanitarian data movement. It then discusses the use of KOS to support humanitarian data, the importance of interoperability, and the need for equal treatment of different languages, 
communities, and cultures. The case of Rohingya refugee crisis is used to illustrate some multilingual, cross-cultural, and social issues in knowledge organization and representation in humanitarian settings.

\section{Open humanitarian data and knowledge creation}

In the humanitarian community, a significant amount of data remains difficult to store and process due to inconsistent schemes, ambiguous concept representations, and unstructured information. Open data, resulting from the global interconnection which is transforming Internet users into data providers, is nonetheless changing the face of humanitarian response and action. What drives the emerging phenomenon of digital humanitarianism is the desire to have un-annotated data better prepared and to create meaningful relationships among information resources (Meier 2015). Its motive is to allow machines to process, infer or combine information sources automatically, and transform them "into useful knowledge representation that depicts the actual crisis needs" (Jihan and Segev 2013, 526).

Recent projects in the open humanitarian data movement such as OpenStreetMap ${ }^{1}$ show how civil society groups are pushing for open platforms and frictionless data mobilizations. Where digital data remains inaccessible, citizens organize themselves to reconstitute information, which is the case of Open Knowledge International ${ }^{2}$. Humanitarian Data Exchange (HDX) ${ }^{3}$, an international open data repository for crisis and humanitarian needs, is an emblematic case of offering homogeneous documentation whose structure has been preserved. This platform employs Humanitarian eXchange Language (HXL), a data standard designed to help improve the sharing and consolidation of data across agencies and move the humanitarian community past its reliance on Excel spreadsheets. However, the still early and uneven nature of the humanitarian data-sharing process in different countries show that the problems of ambiguity, inconsistency, and incompleteness have not been solved. Indeed, knowing to identify, reuse and exchange data, and transform it into knowledge representation that describes the current crisis needs to become a condition for the efficiency of decision making in situations of emergency, natural disaster, and conflict.

\section{The use of KOS to support humanitarian data}

The increasing growth of information, information media, channels, and services leads information professionals to cope with the new needs by developing innovative methods for indexing the ever-growing digital contents and adapting them to new information carriers and repositories. The integration of KOS in digital humanitarian environments would facilitate the integration of the established corpora of recorded

\footnotetext{
${ }^{1}$ See https://www.openstreetmap.org.

${ }^{2}$ See https://okfn.org/.

${ }^{3}$ See https://data.humdata.org/.
} 
knowledge in humanitarian action and digitally generated resources in the emerging open data ecosystem. Publishing of KOS on the Web opens many opportunities for exploiting KOS that were not straightforwardly available:

- KOS provide a standardized way of expressing data and make meaningful relationships between data points. They help improve information flow for decision-makers, helping them allocate resources for response activities.

- KOS record knowledge orders and structures. They can thus relate obsolete knowledge and deprecated terminology with current activities, enhancing evidence and learning each time new knowledge is generated.

- KOS offer terminology hints, evidence of cultural and sociological phenomena from the past. In this way, KOS can raise awareness of potential users and their needs and improve humanitarian performance.

Universal knowledge classifications, as "language independent concept schemes" (Slavic 2011, 23), can assist humanitarian responders in presenting information and formulating queries. The idea behind SKOS and standards such as ISO/IEC 13250 Topic Maps and BS 8723 Structured Vocabularies for Information Retrieval is that "the availability and exchange of controlled vocabularies of various kinds, and subject indexing languages in an open networked environment may contribute to resource discovery through referencing, resolving language ambiguities and providing semantic context for text processing" (Slavic 2011, 44). The application of universal knowledge classification could contribute to not only better resource discovery in emergency response and relief coordination but also improving terminological and research tools for knowledge transfer between clusters/sectors such as Education, Health, Shelter, Water and Sanitation, among others. In the next section, the Rohingya humanitarian case is used to illustrate certain important points in the representation of knowledge and resource description terms in the context of cultural and linguistic diversity.

\section{Integration of knowledge: the Rohingya case}

Since violence broke out against the Rohingya in 2012, more than half a million Rohingya Muslims have fled their homes in Myanmar's Rakhine province. In October 2017, the UN Refugee Agency (UNHCR) described the Rohingya's situation as the "world's fastest growing refugee crisis." ${ }^{4}$ The Rohingya case can provide a context to highlight intervening factors that may influence ethical decisions made by the information professional, namely cultural patterns, social usefulness, social responsibility, respect for oneself, respect for other individuals and institutions, among others (Froehlich 1994). On the HDX platform, there are 22 datasets related to Rohingya displacement; 11 of which are geographical data. In data.world ${ }^{5}$, there are

\footnotetext{
${ }^{4}$ See http://www.unhcr.org/news/press/2017/10/59e4c17e5/joint-statement-rohingya-refugee-crisis.html.

${ }^{5}$ See https://data.world/.
} 
seven projects and datasets related to health facilities in refugee sites, need and population monitoring, and settlement infrastructure. Below, we examine some issues concerning resource description and discovery that classification schemes ought to take into account.

\section{Stateless status}

Under Myanmar's 1982 citizenship law, a million Rohingyas were stripped of citizenship, leaving them stateless and without access to education, healthcare, freedom of movement, and liberty, among others. In Myanmar, the term "Rohingya" itself is taboo and Buddhist leaders refer to Rohingya as "Bengali" instead. The term "stateless," as well as "resident foreigners" and "associate citizens," should be distinguished while constructing or consulting classification schemes, as the legal differences between them can have life-changing consequences.

\section{Refugee, migrant, internally displaced people (IDP)}

According to the UN High Commissioner for Refugees, hundreds of thousands of Rohingya have sought refuge in nearby countries; the vast majority of them migrate to Bangladesh. The question of classifying someone as a refugee, not just a migrant, has complex legal implication and is extremely important because refugees have a right to be protected under international law and cannot be forced to return home.

Another marginalization issue in this displacement is the category of IDP, which has received scant international attention. According to UNHCR, the UN Refugee Agency, "IDPs stay within their own country and remain under the protection of its government, even if that government is the reason for their displacement" 6 ; therefore, they are among "the most vulnerable in the world." Some widely used classification systems have decided not to include this concept. For example, the Library of Congress Subject Headings (LCSH) does not contain "internally displaced people" but only "internal migrant" (Library of Congress 2017), which can only be seen as a term related to the former.

\footnotetext{
${ }^{6}$ See http://www.unhcr.org/internally-displaced-people.html.
} 
Figure 1: The heading "internal migrant" in the $39^{\text {th }}$ edition of LCSH

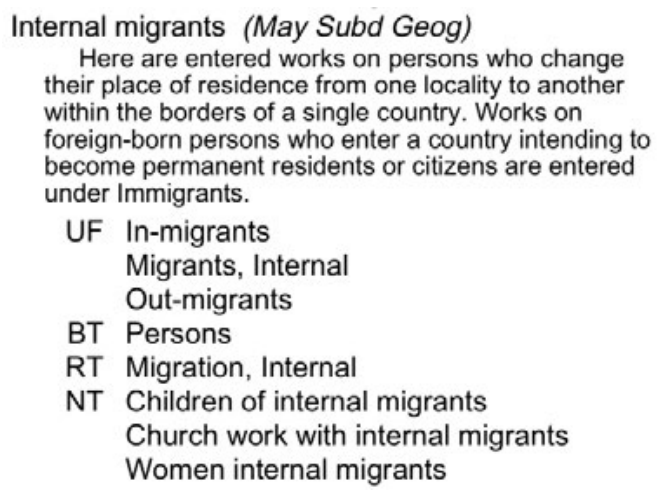

Regarding activities of knowledge organization and representation, some authors have raised concerns about the bias in the representation of concepts related to prejudice and discrimination (Berman 1993), the negligence of the indexer in choosing terms (Dahlberg 1992), the non-neutrality of the subject and undeniable damage to the user (Milani and Guimarães 2011). A term such as "internal migrants" can carry different connotations in humanitarian action than in urban education or labor relations. A synthetic approach, "placing domain analysis within the context of a comprehensive classification" incorporating interdisciplinarity, can be considered in coping with the challenge of semantic ambiguity (Szostak, Gnoli, and López-Huertas 2016, 145).

\section{Islamic practices and social customs of the Rohingya}

The Rohingya's religious orientation (Muslim) and racial antecedents (Bengali) had not been recognized by Myanmar's leaders whose majority are Buddhist and speak their own dialect (Agrawal 2018). Extreme levels of discrimination coming from extremist groups is a break from how Rohingya communities used to be treated. To avoid prejudice and errors of bias, we should take into account the socio-cultural context. Multiple authority identifiers and cross-references can be used to reflect the languages used in addressing these topics more accurately. The preliminary assessment of socionormative values, beliefs, and practices of the Rohingya (see Table 1) is vital to recommending appropriate humanitarian responses regarding health, wellbeing, and the protection of children, adolescents and women (Ripoll 2017). 
Table 1: Examples of terms and variations related to Rohingya Islam

\begin{tabular}{|c|c|c|}
\hline Descriptor & Variations & Notes \\
\hline \multicolumn{3}{|c|}{ Health and well-being } \\
\hline jinn & $\begin{array}{l}\text { djinn (French), dschinn (German), dżinn } \\
\text { (Polish); genie (related term) }\end{array}$ & Spirits in Islamic mythology \\
\hline wudu & $\begin{array}{l}\text { ôzu (Bengali); Lamaz ecar (Chechen); abdest } \\
\text { (Albanian, Polish, Turkish); woedoe (Dutch); } \\
\text { ablution (related term) }\end{array}$ & Obligatory ritual washing \\
\hline kabiraj & boiddah, hakime (Rakhine dialects) & $\begin{array}{l}\text { Local healer who uses herbal } \\
\text { medicine; doctors who heal jinn } \\
\text { possession (Ripoll 2017) }\end{array}$ \\
\hline \multicolumn{3}{|c|}{ Protection of children, adolescents and women } \\
\hline purdah & $\begin{array}{l}\text { pardah (variation); parda (German); paranja } \\
\text { (related term) }\end{array}$ & Practice of female seclusion \\
\hline burqa & $\begin{array}{l}\text { burkha, bourkha, burka, burqua, burqu' } \\
\text { (variations); boerka (Dutch) }\end{array}$ & Veil to conceal the face and body \\
\hline hijab & $\begin{array}{l}\text { hidschab (German); hidzsáb (Hungarian); } \\
\text { tesettür (Turkish); headscarve (related term) }\end{array}$ & $\begin{array}{l}\text { Veil to cover the head and neck but } \\
\text { leaves the face clear }\end{array}$ \\
\hline waqf & $\begin{array}{l}\text { vakuf (Bosnian, Slovenian); wakf (Polish); vakf } \\
\text { (Czech) }\end{array}$ & $\begin{array}{l}\text { Charitable endowment under Islamic } \\
\text { law }\end{array}$ \\
\hline \multicolumn{3}{|c|}{ Social customs } \\
\hline jumu'ah & $\begin{array}{l}\text { jum'aa (Bengali); yumu'ah (Spanish); cuma } \\
\text { namazı (Turkish) }\end{array}$ & Friday prayer \\
\hline \multicolumn{3}{|c|}{ Social solidarity } \\
\hline zakat & $\begin{array}{l}\text { zekat (Bosnian); azaque (Spanish); zacate } \\
\text { (Walloon) }\end{array}$ & Form of mutual aid to help the poor \\
\hline
\end{tabular}

These above examples show the importance of language translation in disaster response and the role of KOS in producing an improved mode of communicating with communities and people affected. From a cultural perspective, knowledge organization processes, tools, and products "suffer a direct impact from cultural diversity" (Guimarães 2017, 92). The tension between Otlet's universalist vision and the culturally anchored "local" remains a fundamental theme in classification, authority control, and links for expanding resource discovery from a local perspective to the global environment. Use of multilingual authorities and multiple authority identifiers 
can be helpful as a means of structuring information in the intercultural interface. KOS tool design and implementation implies considering the integration of multiple authorities, through multilingual authorities and multiple authority identifiers, to accommodate the cultural warrants necessary to assure equal treatment among communities and cultures.

\section{Conclusion}

The pervasive power of digitization and open data causes scientific, educational, economic and cultural communities to change modes of accessing, sharing and disseminating knowledge. In the humanitarian domain, the goal of open data initiatives is to improve information exchange during extreme situations and the effectiveness of humanitarian response. Although significant efforts have been made regarding the systemic and semantic heterogeneity of data, culture heterogeneity in this domain remains largely unaddressed. We need to take into consideration cultural diversity in designing KOS and modes of access to humanitarian knowledge.

The Rohingya case is presented to illustrate certain multilingual, cross-cultural, and social issues in the representation of knowledge in the context of cultural and linguistic diversity. It was chosen not only because of its humongous scale and multidimensionality in terms of humanitarian needs, but also the implications of the cultural confrontation that took place.

This paper emphasizes the importance of an information architecture which could serve as a model in local KOS, and their interoperability with global KOS. It will be a step towards the increasing participation and interaction of different knowledge communities in improving KOS terminology and enhancing integration of knowledge in the humanitarian sector.

\section{References}

Adler, Melissa A., Joseph T. Tennis, Daniel Martínez-Ávila, José Augusto Chaves Guimarães, Jens-Erik Mai, Ole Olesen-Bagneux, and Laura Skouvig (2016). Global/local Knowledge

Organization: Contexts and Questions. Proceedings of the Association for Information Science and Technology 53(1):1-4.

Agrawal, Pawan (2018). Rohingyas: Victims of Reverse Social Engineering. Defence and Security Alert 9(4). New Delhi: 2.

Barát, Ágnes Hajdu (2008). Knowledge Organization in the Cross-Cultural and Multicultural Society. In Advances in Knowledge Organization, Vol. 11: Culture and Identity in Knowledge Organization, Proceedings of the Tenth International ISKO Conference, Montréal, Canada, 91-97. Ergon Verlag.

Beghtol, Clare (2002). "Universal Concepts, Cultural Warrant and Cultural Hospitality." Advances in Knowledge Organization, Vol. 8: Challenges in Knowledge Representation and Organization for the 21st Century, Proceedings of the Seventh International ISKO Conference, Granada, Spain, 45-49. 
Beghtol, Clare (2005). "Ethical Decision-Making for Knowledge Representation and Organization Systems for Global Use." Journal of the American Society for Information Science and Technology 56 (9):903-12.

Berman, Sandford (1993). Prejudices and Antipathies: A Tract on the LC Subject Heads Concerning People. Jefferson, NC: McFarland \& Company.

Dahlberg, Ingetraut (1992). "Ethics and Knowledge Organization: In Memory of Dr. S.R. Ranganathan in His Centenary Year.” International Classification 19 (1):1-2.

Froehlich, Thomas J. (1994). "Ethical Concerns of Information Professionals in an International Context." In New Worlds in Information and Documentation. Amsterdam: Elsevier, edited by José Ramon Alvarez-Ossorio and Ben G. Goedegebuure, 459-70. Amsterdam: Elsevier.

García Gutiérrez, Antonio Luis (2002). "Knowledge Organization from a 'Culture of the Border': Towards a Transcultural Ethics of Mediation.” In Advances in Knowledge Organization, Vol. 8: Challenges in Knowledge Representation and Organization for the 21st Century, Proceedings of the Seventh International ISKO Conference, Granada, Spain, 516-22.

Guimarães, José Augusto Chaves (2017). "Slanted Knowledge Organization as a New Ethical Perspective." In The Organization of Knowledge: Caught between Global Structures and Local Meaning, edited by Jack Andersen and Laura Skouvig, 87-102. Emerald Group Publishing.

Hudon, Michèle (1997). "Multilingual Thesaurus Construction-Integrating the Views of Different Cultures in One Gateway to Knowledge and Concepts." Information Services \& Use 17 (2/3):111-23.

Hudon, Michèle (1999). "Accessing Documents and Information in a World without Frontiers." The Indexer, London.

Jihan, Satria Hutomo, and Aviv Segev (2013). "Context Ontology for Humanitarian Assistance in Crisis Response." In ISCRAM.

Keßler, Carsten, and Chad Hendrix (2015). "The Humanitarian eXchange Language: Coordinating Disaster Response with Semantic Web Technologies.” Semantic Web 6 (1). IOS Press:6-21.

Li Liew, Chern (2004). "Cross-Cultural Design and Usability of a Digital Library Supporting Access to Maori Cultural Heritage Resources: An Examination of Knowledge Organization Issues." In Advances in Knowledge Organization, Vol. 9: Knowledge Organization and the Global Information Society, Proceedings of the Eighth International ISKO Conference, London, UK, edited by Ia C. McIlwaine, 127-32. Würzburg: Ergon Verlag.

Library of Congress (2017). Library of Congress Subject Headings. 39thed. University of California, Berkeley. https://www.loc.gov/aba/publications/FreeLCSH/freelcsh.html.

López-Huertas, Marí-a (2008). "Some Current Research Questions in the Field of Knowledge Organization.” Knowledge Organization 35 (2-3). Ergon:113-36.

López-Huertas, Marí-a (2016). "The Integration of Culture in Knowledge Organization Systems." In Advances in Knowledge Organization, Vol. 15: Knowledge Organization for a Sustainable World, Proceedings of the Fourteenth International ISKO Conference, Rio de Janeiro, Brazil, 13-28. International Society for Knowledge Organization. 
Maio, Paola Di (2007). "An Open Ontology for Open Source Emergency Response System.” Open Source Research Community, 1-12.

Meier, Patrick (2015). Digital Humanitarians: How Big Data Is Changing the Face of Humanitarian Response. Crc Press.

Milani, Suellen Oliveira, and José Augusto Chaves Guimarães (2011). "Problemas Éticos Em Representação Do Conhecimento: Uma Abordagem Teórica.” DataGramaZero: Revista de Ciência Da Informação 12 (1).

Mustafa El Hadi, Widad (2015). "Cultural Interoperability and Knowledge Organization Systems.” In Organização Do Conhecimento E Diversidade Cultural, Proceedings of the 3rd Brazilian ISKO-Conference, edited by José Augusto Chaves Guimarães and Vera Dodebei, 575-606. Marília, São Paulo: Fundação para o Desenvolvimento do Ensino, Pesquisa e Extensão (FUNDEPE).

Ripoll, Santiago (2017). "Social and Cultural Factors Shaping Health and Nutrition, Wellbeing and Protection of the Rohingya within a Humanitarian Context." Institute of Development Studies (UNICEF). http://opendocs.ids.ac.uk/opendocs/handle/123456789/13328.

Slavic, Aida (2011). “Classification Revisited: A Web of Knowledge.” In Innovations in Information Retrieval: Perspectives for Theory and Practice, edited by Allen Foster and Pauline Rafferty, 23-48. London: Facet.

Szostak, Rick, Claudio Gnoli, and Marí-a López-Huertas (2016). Interdisciplinary Knowledge Organization. Berlin: Springer.

Tran, Quoc-Tan (2017). "Ethically Responsible Knowledge Organization Systems: Towards an Intercultural User Interface." Zagadnienia Informacji Naukowej [Journal of Information Science] 55 (2):16-29.

Warner, Alexandra, and Alice Obrecht (2016). "Standardising Humanitarian Data for a Better Response: The Humanitarian eXchange Language. HIF/ALNAP Case Study." London: ODI/ALNAP. 